ISSN 0104-4443

Licenciado sob uma Licença Creative Commons

\title{
Narrativa e história acerca do conceito freudiano de construção
}

\author{
Narrative and history \\ about the Freudian concept of construction
}

\section{Carlota lbertis}

Docente do Programa de Pós-graduação em Filosofia da UFBA, e-mail: carlota.ibertis@ufba.br

\section{Resumo}

O presente artigo propõe-se evidenciar aspectos epistemológicos do conceito freudiano de construção. Elaborada pelo analista com base nas lembranças do analisando, a construção é um recurso heurístico no marco do processo analítico que requer corroboração. Tal exigência deve-se a que o seu resultado deve expressar a verdade do sujeito e não apenas coerência e verossimilhança com as suas recordações, podendo ser concebido, portanto, como uma narrativa verdadeira. As noções de trama e de saber conjetural pertencentes às concepções historiográficas de Paul Veyne e Carlo Ginzburg, respectivamente, fornecem subsídios para a abordagem proposta, que enfatiza o aspecto narrativo do saber de si procurado em análise.

Palavras-chave: Narrativa. Trama. Lembranças. Verdade subjetiva. Saber conjetural. 


\section{Abstract}

This paper explores epistemological aspects of the Freudian concept of construction. Developed by the analyst on the basis of the patient's memories, a construction is a heuristic resource used in the analytic process that requires corroboration. Such demand stems from the need that its result should express the subject's truth, not just consistency and believability with their memories and can be conceived, therefore, as a true narrative. The notions of plot and conjectural knowledge as found in historiographers Paul Veyne and Carlo Ginzburg's conceptualisations respectively, provide a point of departure for the proposed approach that emphasizes narrative aspect of self-knowledge in analysis.

Keywords: Narrative. Plot. Memories. Subjective truth. Conjectural knowledge.

\section{Lembranças e narrativa}

Em análise, a biografia de cada um é revisitada desde o presente transferencial com os elementos fornecidos pelas repetições, pelos sintomas, pelas recordações, pelos sonhos do analisando e pelas interpretações e construções propostas pelo analista. Todavia, qual é o estatuto dessa biografia assim revisitada? A renovação resultante obedece a que constantemente se acrescentam novos eventos e circunstâncias ou a que, com base nos mesmos fatos, haveria mais de uma biografia possível?

Esses interrogantes já clássicos em torno da prática psicanalítica trazem, mais uma vez, questões acerca da recuperação, da interpretação e da construção. Por uma parte, em Construções em análise, Freud considera a construção, proposta pelo analista, a serviço da recuperação de lembranças do analisando. Por outra, as diferenças no trabalho analítico quando se trata de recordações lacunares pontuais e quando se trata da nossa biografia como um todo, remetem às diferenças entre interpretação e construção. Em todos os casos cabe a questão epistemológica acerca da verdade ou da verossimilhança dos resultados alcançados. 
A despeito da grande variedade de formas em que as recordações podem se apresentar ${ }^{1}$, em geral, quando recordamos algo tentamos sempre o mesmo, a saber, inseri-lo em uma trama de circunstâncias e ações concebidas como condições, causas, motivos e efeitos. De modo semelhante, porém mais abrangente, quando se trata do conjunto de todas as nossas recordações, cria-se uma narrativa unificada ${ }^{2}$.

Sobre o caráter lacunar e fragmentário da memória há consenso. Todavia não o há acerca de qual seja a explicação disso. Como sabido, Freud considera que o conflito entre forças psíquicas contrárias desemboca em recalque, explicando o aspecto lacunar e fragmentário. Diversamente, para a neurologia atual as lacunas da memória são preenchidas, na verdade, por interpretação com base nos traços conservados (ROSENFIELD, 1994, p. 76 e ss.), pois os que faltam são considerados perdidos ${ }^{3}$.

Aqui, o que interessa para nós é a característica narrativa do rememorar. Eventos, situações, desejos, sentimentos são ou podem ser recordados com maior ou menor nitidez e fidelidade, mas, ao fazê-lo, os incluímos em um encadeamento causal. Justamente, esse encadeamento integrando uma sucessão de eventos em uma unidade de ação é o que distingue a narrativa (BREMOND, 2008, p. 118) $)^{4}$ Quando o relato estabelece o ordenamento de fatos que constituem as lembranças da própria vida de quem relata, dizemos que se trata de uma narrativa autobiográfica ${ }^{5}$, expressão da própria identidade ${ }^{6}$.

1 Ao longo da sua obra, Freud refere-se a recordações sob a forma de imagens auditivas, sonoras, cenas, palavras, pensamentos, histórias, fragmentos oníricos.

2 Embora em um horizonte teórico bem diferente, Ryle caracteriza a memória como aptidão a narrar (1967, p. 239-241).

3 Segundo Rosenfield, Freud ter-se-ia enganado ao postular a conservação dos traços mnêmicos recalcados.

4 Além de lembrar acontecimentos e circunstâncias pontuais, podemos lembrar da narração que fizemos ou fazíamos encadeando os eventos lembrados como se fosse uma lembrança de segundo grau: a lembrança de como evocamos de forma encadeada certos eventos. Ambos os tipos de recordações parecem misturar-se até tornarem-se indiscerníveis e, no entanto, são diferentes.

5 Philippe Lejeune em 0 pacto autobiográfico observa a coincidência, característica da narrativa autobiográfica, entre narrador, autor e personagem.

6 Embora relevante, 0 exame das diferenças entre a narrativa em segunda pessoa, proposta pelo analista, e a narrativa em primeira pessoa, assumida pelo analisando, não será feito aqui, permanecendo como tarefa futura. 
Nos Estudos sobre histeria, Freud apresenta suas pacientes por meio do relato das respectivas vidas. Inicialmente, o relato apresenta-se incompleto: há uma incógnita a desentranhar que, uma vez descoberta, dá fechamento ao relato. Segundo Freud, o tratamento propõe-se preencher as lacunas desse relato com base nas recordações do analisando e nas ocorrências associativas que elas provoquem. No seu propósito, a psicanálise tiraria proveito da tendência espontânea no ser humano a narrar.

Quanto a essa tendência, em nota ao caso Emmy von N., Freud fala da necessidade psíquica de manter os conteúdos conscientes em uma unidade segundo o princípio de causa-efeito, compelindo, amiúde, a estabelecer falsos enlaces quando os verdadeiros não estão disponíveis:

parece haver uma necessidade de por fenômenos psíquicos dos que nos tornamos conscientes em um enlace causal com outro elemento consciente. Toda vez que a causa efetiva se subtrai da percepção da consciência, ensaiamos sem vacilar outro enlace no que acreditamos ainda que seja falso (BREUER; FREUD, [1893-95] 1976, v. II, parte 2, p. 88).

Nessa concepção, a vida psíquica apresenta-se como fluxo associativo contínuo em relação ao qual o patológico é ruptura. O relato biográfico sempre supõe uma ordenação causal que poderá apresentar-se de forma lacunar ou não. O processo analítico irá corrigir e/ou completá-lo de acordo com a ideia de que a melhor narrativa é aquela que apresenta uma estrutura causal mais clara.

Embora interdependentes, é preciso distinguir três questões: em primeiro lugar, a do caráter lacunar ou completo das recordações; em segundo lugar, a do caráter narrativo ou pontual das recordações e em terceiro lugar, a da possibilidade de mais de uma narrativa para os mesmos fatos lembrados. A primeira diz respeito à possibilidade, ou não, de conservação na memória e, portanto, da recuperação de todas as vivências. A segunda refere-se à modalidade em que as vivências são lembradas - se alinhavadas em um discurso causal ou, ao contrário, apresentadas de forma isolada. A terceira faz alusão à diferença entre a verossimilhança e a verdade 
das narrativas biográficas. No que segue, vamos nos ocupar dessas duas últimas questões.

Em outras palavras, indagamos qual é o estatuto epistemológico do acrescentado pela narrativa ao efetivamente lembrado e ao saber de nós mesmos segundo a teoria freudiana. Partimos do entendimento de Todorov (1979, p. 21) acerca da constituição da narrativa "na tensão entre o inexorável caos do curso dos acontecimentos e a tentativa de lhe impor uma ordem, de lhe dar um sentido" de modo que, para além da verdade das recordações dos fatos isolados, é preciso examinar as relações entre a verdade e as tramas que sustentam as narrativas biográficas, das quais as autobiográficas constituiriam um subtipo.

\section{A narrativa histórica}

Paul Veyne se vale da noção de trama para caracterizar o método histórico. A história nem trabalha com fatos isolados, nem pretende abranger a totalidade dos acontecimentos. A escolha do assunto é livre, mas, já definido este, as ligações entre os fatos são objetivas. O tecido da história é, segundo o historiador, a trama, "de uma mistura muito humana e muito pouco científica de causas materiais, de fins e de acasos; de um corte de vida que o historiador tomou, segundo sua conveniência, em que os fatos têm seus laços objetivos e sua importância relativa..." (VEYNE, 1992, p. 28).

De forma semelhante ao enredo da ficção literária, a trama histórica evidencia o encadeado das ações, organizado não necessariamente de maneira cronológica. No exemplo de Veyne, a trama da revolução de Galileu coloca este em choque com os esquemas da física setecentista, com as suas aspirações, com referências ao platonismo e ao aristotelismo, etc. A trama realça a disposição interna e a inter-relação de fatos, circunstâncias e fins nos acontecimentos.

Um acontecimento pode ser inserido em diversas tramas e aspectos de diversas tramas podem compor um acontecimento. $\mathrm{O}$ historiador decide o percurso para descrever o campo factual, porém dois historiadores que tomem o mesmo caminho têm condições de discutir objetivamente sobre o mesmo. A história é subjetiva no recorte de seu 
problema, mas o campo das ligações entre fatos é suscetível de descrição objetiva. Por isso, a história é relato, mas relato que aspira a uma verdade (mesmo que parcial). Aqui Veyne distingue entre o caráter subjetivo da história em razão da escolha do tema e o caráter relativo da narrativa enquanto não ter critérios de decisão entre diversas narrativas. Nesse sentido, ele nega que a história seja relativa.

Em síntese, história não explica nem deduzindo, nem predizendo, nem procurando princípios que tornem o acontecimento inteligível, mas sim explicitando os diversos episódios que completam uma trama. Nessa trama, os incidentes podem ser chamados de causas superficiais; as condições objetivas, de causas materiais; e a deliberação, de causa final. A história seria uma narração formada de intenções, ações e acasos que pretende alcançar a verdadeira ligação entre os mesmos, ou seja, a ligação objetiva (VEYNE, 1992, p. 52 e ss.).

A prática psicanalítica aproxima-se da reconstrução na história de uma trama também formada por incidentes, circunstâncias e intenções que ela entrelaça. A história individual seria uma narração cuja inteligibilidade dependeria do sucesso em alinhavar tais intenções e contingências de forma satisfatória. O sentido da história residiria, justamente, na trama. Contudo, cada conjunto de fatos, circunstâncias e intenções pode ser contemplado por mais de uma trama narrativa. Aqui, como na história, está em jogo a relação entre verossimilhança e verdade. Freud, como Veyne, defendem as respectivas verdades - e não apenas a verossimilhança - das narrativas estabelecidas.

Salientar o caráter narrativo do saber histórico não significa, necessariamente, extrair conclusões relativistas ou céticas a seu respeito. Ginzburg também defende que o objetivo da historiografia é a verdade, ao mesmo tempo em que salienta o seu aspecto narrativo. Ele evidencia o vínculo entre história e retórica, porém, enxergando nisso argumentos a favor da tese contrária à dos autores que defendem, com base na mesma aproximação, que a eficácia - e não a verdade - seria o objetivo último do historiador.

O ensaio Sobre Aristóteles e a história, mais uma vez debruça-se sobre as provas dos diferentes tipos de retórica. A retórica judiciária aproxima-se 
da historiografia ${ }^{7}$ enquanto reconstrução de eventos com base em indícios ou rastos. Para nenhuma dessas disciplinas se trataria, simplesmente, de convencer, mas de convencer da verdade. Para tanto, servem-se não apenas do âmbito do verossímil, mas também de indícios que apresentam relações naturais e necessárias (GINZBURG, 2002a, p. 57).

Assim, para ambos os autores, a narrativa histórica é o resultado do trabalho do historiador por descobrir a verdade das relações causais de um conjunto de fatos, com base em elementos cujo caráter probatório é justificadamente aceito. Nesse sentido, a narrativa histórica inserir-se-ia na longa tradição do saber conjetural (GINZBURG, 1991, p. 89 e ss.). Na mesma tradição abrevaria a psicanálise.

\section{Construção, verdade e narrativa}

Laplanche em seu artigo "Interpretar [com] Freud" salienta a especificidade da interpretação freudiana que supõe a existência de um sentido a ser reencontrado e não criado, mas também observa que certas leituras do conceito de sobredeterminação enfatizam a ideia de pluralidade de sentidos possíveis, podendo sugerir que todos seriam igualmente válidos (LAPLANCHE, 1988). Entretanto, em Estudos sobre histeria, Freud estabelece níveis de profundidade na distribuição de lembranças e suas séries associativas, que correspondem a graus de resistência, definindo relações hierárquicas de determinação (BREUER; FREUD, [1893-95] 1976, v. II, parte 4, p. 294). Isso sugeriria que, embora diferentes sentidos pudessem ser válidos, haveria um originário que seria determinante dos outros.

Em todo caso, a questão da verdade em Freud apresenta-se nuançada. Na 35믐 das Novas conferências de introdução à psicanálise, lemos que a meta do trabalho científico é a verdade entendida como a concordância com a realidade exterior (FREUD, [1933] 1976, v. XXII, p. 157). Logo a seguir, Freud critica a posição que considera a verdade científica como ilusão resultante de necessidades mutáveis. De forma explícita, ele rejeita a

7 Ginzburg refere-se à historiografia tal como entendida por Tucídides e os discípulos de Aristóteles. 
tese de que qualquer opinião seja tão verdadeira quanto falsa. Isso acarretaria a consequência inadmissível para Freud da impossibilidade de imputar erro (FREUD, [1933] 1976, v. XXII, p. 162-163).

Todavia, a noção freudiana de realidade não é monolítica: desdobra-se em realidade psíquica e realidade material. Já no Projeto aparece uma primeira versão em termos de realidade do pensar e realidade exterior (FREUD, [1950] 1976, v. I, p. 421). Relacionada com a distinção anterior, posteriormente, Freud distingue entre a verdade material, definida acima como concordância com a realidade exterior - e nesse sentido objetiva - e a verdade histórico-vivencial, caracterizada como contendo um núcleo de verdade ainda que desfigurada - nesse sentido, subjetiva (FREUD, [1937] 1976, v. XXIII, p. 269). A combinação emaranhada de representações e afetos passados, porém, presentes pelos seus efeitos por meio de uma complexa rede associativa, é o cerne dessa noção de verdade subjetiva que não se mostra totalmente tal como é.

Embora Freud afirme que às vezes a convicção de verdade tenha no analisando o mesmo efeito que a recordação ${ }^{8}$, coerência e verossimilhança, apenas, não bastariam. A construção em análise, enquanto montagem de uma trama com base nas lembranças do analisando, é um recurso heurístico, proposto pelo analista, que requer validação. Isso é assim, pois, para Freud, a trama deve evidenciar as ligações efetivas e eficientes - no sentido de terem produzido e ainda produzirem efeitos - na vida do analisando. Trata-se de obter uma "imagem confiável, e íntegra em todas as suas peças essenciais, dos anos esquecidos da vida do paciente" (FREUD, [1937] 1976, p. 260).

Cada construção é uma conjetura a ser examinada e corroborada no decorrer da análise (FREUD, [1937] 1976, p. 266). Embora às vezes possa parecer que Freud adota uma atitude puramente pragmática como critério de validação, para ele as mudanças no processo analítico 9 não acontecem senão quando interpretação e construção tocam a verdade do sujeito (FREUD, [1937] 1976, p. 263). Tanto interpretação

8 Poder-se-ia considerar que com isso Freud abre espaço para as posições que defendem a verossimilhança e utilidade de uma construção como as únicas condições de validez.

9 Freud pressupõe um trabalho, por parte do analista, que conceda a palavra ao analisando e isento de qualquer intenção de sugestioná-lo.

Rev. Filos., Aurora, Curitiba, v. 23, n. 33, p. 315-327, jul./dez. 2011 
quanto construção precisam uma corroboração indireta na continuação da análise por meio, por exemplo, de novas associações adequadas ao conteúdo da construção ou interpretação, uma vez que tanto o assentimento quanto a negação diretos do analisando são equívocos (FREUD, [1937] 1976), p. 264-265. Não se trata, portanto, de não levar em conta a reação do analisando, mas de considerá-la em sua complexidade à luz da continuação da análise.

Pode-se dizer, então, que a trama verdadeira é montada e reconhecida com base em indícios indiretos. De modo que a prática psicanalítica pode ser caracterizada como um saber conjetural (GINZBURG, 1991, p. 89) baseado em indícios, cujo rastro leva, em um primeiro momento, a ordenar causalmente os fatos lembrados em uma narração e, em um segundo momento, a corroborar tal narração.

\section{Narrativas conjeturais e retrospecção}

O trabalho psicanalítico, o detetivesco e o do especialista em arte são exemplos do modus operandi, característico da semiótica médica e conhecido como saber conjetural (GINZBURG, 1991, p. 119-120) ${ }^{10}$. O detalhe, o fenômeno inadvertido e o fato sem relevância pertencem à categoria de signos ou pistas, pontos de partida para a reconstrução de acontecimentos dos quais não há nem testemunhas, nem documentos diretos. Especificamente, o saber conjetural semiótico realiza um movimento regressivo dos indícios até as causas desses. Em Sobre a psicogênese de um caso de homossexualidade feminina, Freud observa o seguinte,

${ }^{10}$ Ginzburg remonta a origem do saber conjetural, caracterizado por contar uma história com base na decifração de sinais, à época dos primeiros caçadores. Com o tempo, esse saber aplica-se em diversos campos constituindo conhecimentos e práticas como a medicina, que visa ao passado, presente e futuro e como a jurisprudência, virada para o passado. Trata-se de conhecimentos e práticas que conjeturam e julgam com base em signos, indícios ou rastros. No século XVIII, o novo impulso dado aos métodos arqueológicos termina de delinear esse modelo conjetural de conhecimento centrado no caso singular e de caráter qualitativo, que se opõe ao modelo galileano de inspiração matemática e experimental (GINZBURG, 1991, p. 99 e ss.). Em Construções em análise, Freud compara a prática psicanalítica com o trabalho do arqueólogo, salientando a tarefa de reconstrução com base em restos conservados, tarefa para a qual a psicanálise teria vantagem sobre a arqueologia no objetivo de conquistar a verdade e não apenas a verossimilhança, uma vez que trabalha com fenômenos de certa forma conservados (FREUD, [1937] 1976), p. 261. 
acerca do tipo de esclarecimento retrospectivo de um processo anímico que se propõe a psicanálise:

[...] o tempo todo que perseguimos o desenvolvimento desde seu resultado final para trás, deparamo-nos com uma trama sem lacunas, e consideramos nossa intelecção acabadamente satisfatória e talvez até exaustiva. Porém, se empreendermos o caminho inverso, se partirmos das premissas descobertas pela análise e procuramos segui-las até o resultado, dissolve-se por completo a impressão de um encadeamento necessário, que não pudesse se determinar de nenhum outro modo. Logo reparamos que também poderia ter resultado algo diverso e que a esse outro resultado também te-lo-ia-mos podido compreender e esclarecer igualmente bem. A síntese não é, portanto, tão satisfatória como a análise; em outras palavras: não estaríamos em condições de prever, conhecendo as premissas, a natureza do resultado (FREUD, [1920] 1976, p. 160).

As índoles do objeto e do propósito da prática psicanalítica não permitem a predição. Ao contrário, trata-se de um saber que parte do efeito e remonta a cadeia de representações. Assim, a psicanálise, enquanto saber conjetural, em primeiro lugar, esclarece os indícios - oferecidos por sintomas, sonhos, atos falhos, esquecimentos - interpretando com base nas associações e reconstruindo a história do sujeito; em segundo lugar, avalia tais esclarecimentos com base nos efeitos provocados pela comunicação destes.

Ora, o procedimento analítico admite a possibilidade de o analista comunicar uma interpretação ou reconstrução que não concordem com a realidade psíquica do analisando. Todavia, o fato de não serem verdadeiras não significa que elas não possam ser aproveitáveis provisoriamente como meios de busca da verdade do sujeito. Mais uma vez a comparação com a história ser-nos-á útil. Ginzburg comenta:

[...] as perguntas do historiador são colocadas sempre, direta ou indiretamente, em formas (destaco o plural) narrativas. Essas narrações provisórias delimitam um âmbito de possibilidades que, frequentemente, são modificadas ou até descartadas no curso do processo de pesquisa. Podemos comparar essas narrativas a instâncias mediadoras entre 
questões e fontes, as quais influem profundamente (ainda que não de maneira exclusiva) sobre os modos pelos quais os dados históricos são recolhidos, eliminados, interpretados - e, por fim, naturalmente, narrados (GINZBURG, 2002b, p. 114).

De modo semelhante podemos conceber o funcionamento das interpretações e reconstruções analíticas. Apresentadas como narrativas, elas estabelecem mediações entre as lembranças e o questionamento presente do analisando, que mesmo não confirmadas, podem abrir um caminho para a continuação do trabalho analítico, introduzindo novas vias associativas. A esse respeito, Ginzburg (2002b, p. 116) tece uma consideração aplicável à psicanálise: [...] "a própria existência de um expediente narrativo pode gerar - tanto direta como indiretamente (removendo uma interdição tácita, por exemplo) - uma via de pesquisa". Com efeito, para Freud, é possível capturar um aspecto da verdade "com auxílio da isca da mentira" (FREUD, [1937] 1976, p. 263).

A especificidade da psicanálise reside em que ela não trata com um passado terminado, mas com um passado que se prolonga no presente e um presente que tinge o passado. A sua dificuldade e a sua riqueza consistem em que as únicas vias de acesso às recordações são as representações presentes. Eis a razão pela qual se poderia concluir que a verdade é algo criado no presente da análise. De fato, a conexão pode ser criada no presente, mas, para Freud, ela atualiza a verdade psíquica do sujeito que, iniciada no passado infantil, é atual na sua eficácia como determinante psíquico, mas não na sua origem. Em outras palavras, a associação atual não surge ex nihilo; ela evidencia uma causalidade anteriormente estabelecida.

\section{Considerações finais}

Os esforços tanto dos historiadores, segundo autores como Veyne e Ginzburg, quanto dos psicanalistas, segundo Freud, orientam-se a descobrir a verdade de acontecimentos passados, estabelecendo narrativas que evidenciam as relações causais entre os fatos. As respectivas 
convicções epistemológicas não resignam tal objetivo teórico, nem o restringem à busca pela eficácia. Entretanto, essas concepções não consideram os elementos narrativos exclusivamente em função do propósito último. A narrativa, além de ser o produto final dos afazeres historiográficos e psicanalíticos, também é concebida como recurso heurístico cuja potencialidade cognitiva nem sempre se aprecia em sua justa medida. Salientar o caráter narrativo dos respectivos produtos procurou evidenciar a singularidade das explicações histórica e freudiana.

\section{Referências}

BREMOND, C. A lógica dos possíveis narrativos. In: BARTHES, R. et al. Análise estrutural da narrativa. Tradução de Maria Zélia Barbosa Pinto. Petrópolis: Vozes, 2008. p. 19-62.

BREUER, J.; FREUD, S. Estudios sobre histeria. In: FREUD, S. Obras completas. Tradução de José L. Etcheverry. Buenos Aires: Amorrortu, 1976. v. 2. Publicado originalmente em 1895.

FREUD, S. Projeto de psicologia. In: FREUD, S. Obras completas. Tradução de José L. Etcheverry. Buenos Aires: Amorrortu, 1976. v. 1. Publicado originalmente em 1950.

FREUD, S. Sobre la psicogénesis de um caso de homosexualidad feminina. In: FREUD, S. Obras completas. Tradução de José L. Etcheverry. Buenos Aires: Amorrortu, 1976. v. 18. Publicado originalmente em 1920.

FREUD, S. 35aㅡ Conferencia de las nuevas conferencias de introducción al psicoanálisis. In: FREUD, S. Obras completas. Tradução de José L. Etcheverry. Buenos Aires: Amorrortu, 1976. v. 22. Publicado originalmente em 1932-1936.

FREUD, S. Construcciones en análisis. In: FREUD, S. Obras completas. Tradução de Etcheverry. Buenos Aires: Amorrortu, 1976. v. 23. Publicado originalmente em 1937. 
GINZBURG, C. Sobre Aristóteles e a história, mais uma vez. In: GINZBURG, C. Relações de força: história, retórica, prova. Tradução de Jônatas Batista Neto. São Paulo: Companhia das Letras, 2002a.

GINZBURG, C. Decifrar um espaço em branco. In: GINZBURG, C. Relações de força: história, retórica, prova. Tradução de Jônatas Batista Neto. São Paulo: Companhia das Letras, 2002b.

LAPLANCHE, J. Interpretar [com] Freud. In: LAPLANCHE, J. et al. Teoria da sedução generalizada. Porto Alegre: Artes Médicas, 1988. p. 21-32.

LEJEUNE, P. O pacto autobiográfico. Tradução de Jovita Noronha e Maria Inês Guedes. Belo Horizonte: Ed. da UFMG, 2008.

ROSENFIELD, I. A invenção da memória. Rio de Janeiro: Nova Fronteira, 1994.

TODOROV, T. As estruturas narrativas. Tradução de Leyla Perrone-Moisés. São Paulo: Perspectiva, 1979.

VEYNE, P. Como se escreve a história. Tradução de Alda Batar e Maria Auxiliadora Kneipp. 2. ed. Brasília: Universidade de Brasília, 1992.

Recebido: 12/05/2011

Received: 05/12/2011

Aprovado: 21/06/2011

Approved: 06/21/2011 